\title{
Determinantes da tensão do cuidador familiar de idosos dependentes
}

\author{
Determinatives of family caregiver's tension while caring the dependent elderly \\ Determinantes de la tensión del cuidador familiar de ancianos dependientes
}

\author{
Maria das Graças Melo Fernandes', Telma Ribeiro Garcia" \\ 'Universidade Federal da Paraíba. Departamento de Enfermagem Médico-Cirúrgica e Administração. João Pessoa, PB \\ "Universidade Federal da Paraíba. Departamento de Pós-Graduação em Enfermagem. João Pessoa, PB
}

Submissão: 10/06/2008

Aprovação: 21/10/2008

\section{RESUMO}

Este estudo objetivou investigar os determinantes da tensão do cuidador familiar de idosos dependentes. Sua efetividade se deu no cenário domiciliar, envolvendo trinta cuidadoras principais. Os dados foram coletados por meio de entrevista estruturada gravada. A análise dos dados objetivos foi feita mediante uma abordagem Quantitativa. Os dados discursivos, coletados por meio da gravação da entrevista, por serem apreendidos a partir de um instrumento estruturado, dispensaram procedimento analítico, sendo distribuídos entre as Questões a Que se referiam no sentido de ampliar sua compreensão. Os resultados apontam Que o fenômeno investigado se origina a partir de determinantes relacionados ao cuidador, aos déficits do idoso, à interação idoso/cuidador, ao ambiente, e às demandas de cuidado.

Descritores: Cuidadores; Idoso; Família; Tensão de vida.

\section{ABSTRACT}

This study had as objective investigate the determinatives of the tension of the dependent elderly's family caregiver. Its accomplish happened in the domestic scenery, involving thirty principal caregivers. The data were collected by a recorded and estructured interview. The analyses of the objective data was made by means of a Quantitative approach. The discursive data, for being collected through a structured instrument, dispensed analytic procedure, being distribute between Questions that referee in the way of amply your comprehension. The results appoint that the investigated phenomenon starts from determinatives related to the caregiver, to the elderly's deficits, to the interection elderly/caregiver, to the environment, and related to the care demands.

Descriptors: Caregivers; Elderly; Family; Stress, psychological.

\section{RESUMEN}

Este estudio objetivó investigar los determinantes de la tensión del cuidador familiar de ancianos dependientes. Su efectividad se dio en el escenario domiciliar, envolviendo a treinta cuidadoras principales. Los datos fueron colectados por medio de entrevista estructurada grabada. El análisis de los datos objetivos fue hecho mediante un abordaje cuantitativo. Los datos discursivos, colectados por medio de la grabación de la entrevista, por ser aprehendidos a partir de un instrumento estructurado, dispensaron procedimiento analítico, siendo distribuidos entre las cuestiones a Que se referían en el sentido de ampliar su comprensión. Los resultados apuntan Que el fenómeno investigado se origina a partir de determinantes relacionados al cuidador, a los déficits del anciano, a la interacción anciano/cuidador, al ambiente, y a las demandas de cuidado.

Descriptores: Cuidadores; Anciano; Família; Estrés psicológico. 


\section{INTRODUÇÃO}

A experiência de assumir a responsabilidade por idosos dependentes tem sido colocada pelos cuidadores familiares como uma tarefa exaustiva e estressante, pelo envolvimento afetivo e por ocorrer uma transformação de uma relação anterior de reciprocidade para uma relação de dependência, em Que o cuidador, ao desempenhar atividades relacionadas ao bem-estar físico e psicossocial do idoso, passa a ter restrições em relação à sua própria vida.

O ônus relacionado ao cuidado de idosos dependentes faz com Que o cuidador familiar deva ser visto, também, como um cliente Que merece ser enfocado criteriosamente. Apesar disso, nos países latino-americanos, ao Que se sabe, esta atividade ainda não está incorporada nos serviços de saúde apesar de já ser levada em consideração há algum tempo nos países desenvolvidos ${ }^{(1)}$.

$\mathrm{Na}$ realidade brasileira, os efeitos da dependência do idoso, sob a família cuidadora têm, ultimamente, determinado algumas intervenções, profissionais e voluntárias, fundamentadas em dados não oriundos de investigações sistematizadas, organizadas e metodologicamente apropriadas ${ }^{(2)}$. Dada essa realidade, este estudo tem como objetivo investigar os determinantes envolvidos na ocorrência da tensão do cuidador familiar de idosos dependentes. O conhecimento desses aspectos relativos ao fenôneno em Questão proporcionará planejamento e intervenções individualizadas para cuidadores familiares, pois serão subsidiadas por suas próprias vivências no cenário da provisão de cuidado.

\section{METODOLOGIA}

O ambiente selecionado para o estudo compreendeu, inicialmente, o Programa de Atendimento ao Idoso do Hospital Universitário Lauro Wanderley - UFPB, onde ocorreu nosso primeiro contato com as cuidadoras, momento em Que foi realizado o convite no tocante à sua participação na pesquisa. Os demais contatos efetivados entre estas e as pesquisadoras ocorreram em seus domicílios, Que, na maioria dos casos, também abrigavam o idoso dependente, constituindo, portanto, o ambiente natural do cuidado.

Participaram desta investigação trinta mulheres Que expressavam evidências biopsicossociais de efeitos deletérios decorrentes do desempenho do papel de cuidadora de seu parente idoso sobre seu bem-estar. A coleta de dados foi realizada por meio de entrevista, gravada, sendo subsidiada por um roteiro estruturado, fundamentado na literatura pertinente, incluindo escalas de reconhecida confiabilidade para avaliar os déficits funcionais do idoso como a escala de Barthel ${ }^{(4)}$ para mensuração da capacidade física e a de Pearlin et al ${ }^{(5)}$ para medida da capacidade cognitiva e distúrbio de comportamento. Também foi utilizada a medida de sensação de sobrecarga por parte do cuidador proposta por essas autoras. As informações contempladas nesse instrumento foram organizadas em cinco categorias: determinantes relacionados ao cuidador, determinantes relacionados aos déficits do idoso, determinantes relacionados à interação idoso/cuidador, determinantes relacionados ao ambiente, e determinantes relacionados às demandas de cuidado.

A análise dos dados objetivos se deu por meio de uma abordagem Quantitativa utilizando-se sistema computacional, através do programa Statistical Package for the Social Sciences. No tocante aos dados discursivos originados da transcrição das entrevistas, por serem apreendidos a partir de um instrumento estruturado, dispensaram procedimento analítico, pois já se referiam aos determinantes da tensão do cuidador pesQuisados na literatura, sendo apenas distribuídos entre as categorias de dados no sentido de ampliar sua compreensão.

Quanto aos aspectos éticos, no desenvolvimento deste estudo, norteamo-nos pelos princípios normativos para a pesquisa envolvendo seres humanos contemplados na Resolução No 196/ 96 do $\mathrm{CNS} / \mathrm{MS} / \mathrm{BRASIL}{ }^{(3)}$. No tocante à instituição, cenário do estudo, encaminhamos protocolo de pesquisa para ser apreciado pelo Comitê de Ética Que referenda a investigação. Às participantes do estudo garantimos consentimento livre e esclarecido (incluindo a menção dos objetivos e dos procedimentos utilizados, a exemplo do sistema de gravação), anonimato, sigilo das informações e respeito à sua privacidade, bem como liberdade para retirar seu consentimento em Qualquer fase da pesquisa sem prejuízos ao seu cuidado.

\section{RESULTADOS E DISCUSSÃO}

\section{Determinantes Relacionados ao Cuidador}

Este item comportou as características sociodemográficas das cuidadoras: idade, estado civil, nível de escolaridade, renda familiar; exercício simultâneo de papéis; co-residência com o idoso; além do estado de saúde da cuidadora, prévio à sua inserção na atividade de cuidar.

A idade das cuidadoras variou entre o mínimo de 21 e o máximo de 72 anos, com média de 50,3 (IC 95\% = \pm 4,16; DP = $11,13)$ e mediana de 50,5 anos. Cinco $(16,7 \%)$ cuidadoras estavam na faixa etária de 20 a 40 anos (adulto jovem); $20(66,6 \%)$ na faixa etária de 41 a 60 anos (adulto de meia idade); cinco (16,7\%), na faixa etária de 61 a 72 anos (adulto idoso).

Cuidadoras jovens encontram-se mais susceptíveis à tensão por se confrontarem com a necessidade de balancear as demandas competitivas dentro da família e no emprego ${ }^{(6)}$. Por seu turno, cuidadoras na meia idade e idosas estão mais predispostas ao impacto negativo do cuidado devido às mudanças associadas ao próprio envelhecimento e pela possibilidade delas apresentarem um estado de saúde parecido com aquele evidenciado pelo receptor de cuidados $^{(7,8)}$.

Quanto ao estado civil, observamos Que $14(46,7 \%)$ cuidadoras eram casadas; dez (33,3\%), solteiras; Quatro (13,3\%), divorciadas e duas $(6,7 \%)$, viúvas. Neste estudo, as mulheres casadas, bem como aQuelas Que possuíam família própria, evidenciavam níveis mais elevados de tensão pelo fato de precisarem equilibrar as necessidades do idoso com as do restante da família ou com a demanda do emprego, o Que está em consonância com os resultados apresentados por outras investigações ${ }^{(10)}$.

O nível de escolaridade das cuidadoras caracterizou-se como baixo: Quatro $(13,3 \%)$ eram analfabetas; sete $(23,3 \%)$ eram alfabetizadas; oito $(26,7 \%)$ haviam concluído o ensino fundamental; sete $(23,3 \%)$ possuíam o ensino médio; Quatro $(13,3 \%)$ tinham formação escolar de nível superior. Foi verificada correlação negativa, significante ao nível de $5 \%$, entre a variável escolaridade 
e as variáveis alteração no estado emocional $(r=-0,396)$ e enfrentamento individual da situação comprometido $(r=-0,435)$. Esses resultados nos permitem inferir Que, Quanto menor o grau de escolaridade da mulher, tanto mais significativas às alterações emocionais Que ela pode evidenciar como resultado da assunção do papel de cuidadora familiar do idoso dependente; e tanto mais ineficaz ou comprometido o modo de enfrentamento individual da situação.

Os dados acerca da escolaridade possuem estreita relação com o baixo nível de renda das famílias de Que as cuidadoras faziam parte: $20(66,7 \%)$ tinham renda mensal de um a três salários mínimos; seis (20\%) recebiam Quatro a seis salários mínimos e Quatro $(13,3 \%)$ tinham provento maior do Que seis salários mínimos. Do mesmo modo, o entrelaçamento do nível educacional e de renda das cuidadoras constitui forte preditor de tensão. Vale salientar Que, Quando a provisão de cuidado transcorre em condições de escassez de recursos materiais, ela tende a ser vista como um dever ou opção sem alternativa pela cuidadora, constituindo, assim, uma atividade estressante ${ }^{(1,9)}$.

O exercício simultâneo de papéis constituiu um elemento gerador de tensão no grupo pesquisado. Observou-se uma correlação positiva, embora moderada $(r=0,370)$, significante ao nível de $5 \%$, entre as variáveis número de papéis sociais exercidos e tensão da cuidadora. No ambiente doméstico, $29(96,7 \%)$ delas lidavam pelo menos com dois papéis, cuidar do idoso e realizar os afazeres da casa. Quanto ao cuidado com os filhos, as 23 (76,7\%) Que eram mães, possuíam filhos adultos jovens Que dispensavam cuidados diretos. No entanto, dentre essas, oito $(34,8 \%)$ cuidavam de netos, mesmo evidenciando problemas Que tornavam penoso para elas assumirem essa nova tarefa.

Além das atividades realizadas no lar, 13 (43,3\%) cuidadoras trabalhavam fora, sendo oito $(26,7 \%)$ com jornada de um turno e cinco $(16,7 \%)$ com horário de trabalho correspondente ao dia todo. Para assumirem o emprego, essas cuidadoras recebiam ajuda de parentes e, especialmente, de empregadas domésticas no cuidado do idoso, como supervisão e administração de medicamentos. Porém, as tarefas mais desgastantes, tais como dar banho e realizar higiene íntima, eram efetivadas por elas antes de saírem para o trabalho, no intervalo para o almoço (nos casos de jornada em dois turnos) ou após seu retorno para o domicílio, Quando assumiam integralmente os cuidados requeridos pelo familiar.

A situação de cuidado interferia de tal modo no emprego das cuidadoras Que, entre as $13(43,3 \%)$ com exercício dessa atividade, nove $(69,2 \%)$ referiram ter faltado ao trabalho: duas $(22,2 \%)$ regularmente e sete $(77,8 \%)$ casualmente. As 13 afirmaram já haver chegado mais tarde ou saído mais cedo do trabalho: sete $(53,8 \%)$, freoüentemente e seis $(46,2 \%)$, às vezes. Além disso, todas elas se preocupavam com o idoso eneuanto estavam no emprego. Essa interferência atingia o nível de satisfação das cuidadoras com a Qualidade do seu trabalho: cinco $(38,5 \%)$ expressavam tal condição de modo freqüente e Quatro $(30,8 \%)$ casualmente. Esses achados estão em consonância com os resultados apontados por outras pesquisas as Quais identificaram correlação entre prejuízos no trabalho formal de cuidadores familiar de idosos, associados às demandas de cuidado, e o aumento de tensão $0^{(6)}$.

O conflito entre papéis experimentado pelas cuidadoras é visto como fonte contínua de tensão e tem induzido muitos autores, a exemplo de $\mathrm{Chou}^{(10)}$, a categorizarem as cuidadoras como "mulheres divididas" (women in the middle) ou como "a geração sanduíche" (the sandwich generation). Cabe destacar Que no contexto deste estudo algumas cuidadoras compreenderam o cenário do trabalho como um local onde se pode obter suporte emocional (aqui você conversa, desabafa... minhas amigas me dão uma força...), além de funcionar, de algum modo, como atividade de lazer.

... Às vezes, minhas colegas dizem: "Por Que você não se aposenta?" Eu não tenho tempo ainda, mas eu não Quero me aposentar. Meu trabalho é Quase um lazer; meu trabalho é um lazer... Já pensou, eu ficar, o tempo todo, dentro de casa? Passar o dia todo com mãe, vai me deixar perturbada. Apesar de que tem algumas horas que eu já estou me sentindo assim (E3).

No Que se refere à moradia, 27 (90\%) dos idosos moravam com a cuidadora devido à dependência mútua (nos casos em Que a cuidadora era esposa ou filha solteira Que não possuíam residência própria) e, ainda, pela necessidade da provedora de cuidados conciliar seus diversos papéis, particularmente o de administrar ou realizar os afazeres da casa com a assistência requerida pelo familiar dependente. Os demais idosos (10\%) residiam em área próxima à casa da cuidadora por possuírem uma estrutura de suporte Que favorecia a ocorrência de tal condição.

Para o idoso, morar com a cuidadora traz benefícios, uma vez Que sua demanda de cuidado tem maior possibilidade de ser atendida de forma imediata e ininterrupta dia após dia. No entanto, para a cuidadora, intensifica sua imersão no papel de cuidar favorecendo, deste modo, maior exposição aos efeitos negativos dessa atividade e, conseqüentemente, a níveis mais elevados de tensão ${ }^{(1)}$.

Quanto ao estado de saúde das cuidadoras anterior à sua inserção na provisão de cuidados, 1 I $(36,7 \%)$ apresentavam alterações Que, de certa forma, já contra-indicava seu engajamento na referida atividade. Os problemas identificados foram epilepsia $(3,3 \%)$; asma e arritmia cardíaca, concomitantemente $(3,3 \%)$; colelitíase (3,3\%); sinusite crônica (3,3\%); câncer de mama $(6,7 \%)$; diabetes $(6,7 \%)$ e hipertensão arterial (10\%). Estes processos mórbidos geram alteração progressiva ou incapacidade residual do organismo e demandam ajustes contínuos no estilo de vida da pessoa acometida. Deste modo, constituem eventos estressores adicionais vivenciados por essas cuidadoras Que lhes predispõem a expressar mais intensamente os efeitos negativos decorrentes da assistência contínua ao idoso.

\section{Determinantes Relacionados aos Déficits do Idoso}

A idade dos idosos variou entre o mínimo de 62 e o máximo de 93 anos, com média de 79,4 (IC 95\% = $\pm 3,33$; DP = 8,91) e mediana de 81 anos. A idade do idoso; em si, não é considerada um déficit, no entanto, constitui fator de risco importante para muitas doenças que tendem a produzir dependência e a assumir dimensões epidêmicas no envelhecimento. Por isto, está sendo aQui apresentada: sete $(23,3 \%)$ idosos estavam na faixa etária de 60 a 70 anos; oito (26,7\%), na faixa etária de 71 a 80 anos; I I (36,7\%), na faixa etária de 81 a 90 anos; Quatro (13,3\%) tinham mais de 90 anos. Este achado tanto expressa a inter-relação existente entre a tríade expectativa de vida, incapacidade e demanda de 
cuidado, como demonstram as pressões exercidas pela população com oitenta anos e mais (composta principalmente de pessoas dependentes) sobre os sistemas de suporte, especialmente sobre $o$ informal ${ }^{(12)}$.

Com relação à capacidade física, todos os idosos apresentavam algum grau de dependência. O escore médio obtido na escala de Barthel $^{(4)}$ foi equivalente a 24,5 (IC 95\% $= \pm 9,41$; DP $\left.=25,2\right)$ e a mediana de 15 pontos. Quatro $(13,3 \%)$ idosos evidenciavam dependência total, $16(53,3 \%)$ dependência muito elevada, seis (20\%) dependência elevada e Quatro (13,3\%) dependência moderada. No tocante à capacidade cognitiva, o escore médio dos idosos foi igual a 22,47 (IC 95\% $= \pm 4,28$; DP $=11,44) \mathrm{e}$ a mediana igual a 28 pontos. Três $(10 \%)$ idosos possuíam esta função de forma preservada, seis (20\%) levemente/moderadamente comprometida e 2 I (70\%) altamente/totalmente comprometida. Distúrbio de comportamento estava presente de forma leve em oito $(26,7 \%)$ idosos, e moderada em 10 (33,3\%); 12 (40\%), não manifestavam este problema. O escore médio obtido pelos idosos na escala de distúrbio de comportamento foi de 18,97 (IC 95\% = $\pm 3,38$; DP $=9,03$ ) e mediana de 14,5 pontos.

Avaliando-se a correlação entre os escores obtidos pelos idosos nas três escalas utilizadas verificou-se uma correlação positiva, embora moderada $(r=0,389)$, significante ao nível de $5 \%$, entre as variáveis dependência física e distúrbio de comportamento. Ou seja, Quanto maior a dependência física do idoso, maiores as chances de Que apresentem distúrbio de comportamento. A variável incapacidade cognitiva não revelou correlação significante com as outras duas.

A incapacidade física do idoso foi forte preditora de tensão no grupo pesquisado por demandar da cuidadora assistência contínua e progressiva nas atividades básicas da vida diária do receptor de cuidados e, conseqüentemente, maior esforço físico e consumo de energia. Conforme se pode inferir pelos resultados apresentados na Tabela I, tanto menor o escore obtido pelo idoso na escala de Barthel maior a demanda de cuidado direto, condição vista pelas cuidadoras como muito difícil.

O déficit de memória do idoso gerava tensão na cuidadora, tanto por determinar incapacidade de manejo da vida prática no receptor de cuidados, produzindo maior exigência de suporte, como por prejudicar a comunicação e, conseQüentemente, a reciprocidade da relação existente entre ambos, Que ocorria, na essência, a partir da provisão unilateral de cuidados, e não, por exemplo, através da confidência de sentimentos, fato Que despertava tristeza nas cuidadoras.
... Nada mais ela entende, sempre eu digo "Eu estou sozinha. Não tenho com Quem conversar"... Porque ela era Quem me entendia (choro) ... Às vezes eu converso com ela, digo "Oh, mamãe, converse comigo!"(E25).

As alterações comportamentais do idoso tiveram um impacto negativo na vida das cuidadoras por tensionar suas relações, tanto com o receptor de cuidados, Quanto com os demais membros da família, além de ser um problema Que exigia delas ficar alerta a maior parte do tempo em relação ao idoso.

...Ela diz "é, é, é..." de manhã até de noite! Quando chega de noite, de tanto eu ouvir "é, é, é...", penso que minha cabeça vai explodir!(E8).

Alguns autores afirmam Que cuidar de um idoso incapacitado mentalmente causa mais tensão do Que cuidar de um idoso somente com incapacidade física ${ }^{(13)}$. Outros, não encontraram diferenças Quando compararam respostas dos cuidadores de três grupos de idosos: com deficiência cognitiva, com deficiência física ou com mudanças comportamentais ${ }^{(7)}$.

\section{Determinantes Relacionados à Interação Idoso/Cuidador}

Quanto ao grau de parentesco entre cuidadoras/receptores de cuidado, observamos 21 (70\%) filhas, sete $(23,3 \%)$ esposas, uma $(3,3 \%)$ sobrinha e uma $(3,3 \%)$ neta. Todos os idosos casados eram cuidados por suas esposas; os viúvos eram cuidados em sua maioria pelas filhas, especialmente pelas solteiras, divorciadas ou também viúvas. Cabe destacar Que na vida familiar, existe uma hierarQuia de compromisso em relação ao cuidado: em primeiro lugar, vem a esposa e, em seguida, a filha solteira ou Que vive sozinha. Raramente o cuidador é outro parente, uma pessoa jovem, ou um homem ${ }^{(14)}$.

Diferentes pesQuisas ${ }^{(6,15)}$ demonstram Que, Quanto mais próximo o grau de parentesco entre cuidador/receptor de cuidados, maior o prejuízo na saúde mental do cuidador. Isso ocorre tanto pelos laços afetivos, como pelas expectativas socioculturais, Que aumentam a responsabilidade do cuidador no tocante à provisão de assistência ao parente incapacitado, a despeito de suas condições pessoais e sociais, implicando maiores custos, especialmente para as filhas que têm família própria. Para as esposas, o ato de cuidar de seu cônjuge está embutido no seu papel de mulher casada, a partir do compromisso em engajar-se num projeto de vida em comum assumido por ocasião do matrimônio, o Que pode funcionar

Tabela 1. Correlação entre os diferentes aspectos envolvidos na demanda de cuidado direto e o escore do idoso na escala de Barthel - João Pessoa, 2003.

\begin{tabular}{|c|c|c|c|c|c|c|}
\hline & Dá banho & $\begin{array}{l}\text { Faz higiene } \\
\text { íntima }\end{array}$ & Veste o idoso & $\begin{array}{c}\text { Ajuda na } \\
\text { locomoção }\end{array}$ & $\begin{array}{c}\text { Ajuda na } \\
\text { alimentação }\end{array}$ & $\begin{array}{c}\text { Escore da } \\
\text { escala de } \\
\text { Barthel }\end{array}$ \\
\hline Dá banho & 1,000 & & & & & \\
\hline Faz higiene íntima & $871 * *$ & 1,000 & & & & \\
\hline Veste o idoso & $.926 * *$ &, $807 * *$ & 1,000 & & & \\
\hline Ajuda na locomoção & $.556 * *$ &, $484 * *$ & $.494 * *$ & 1,000 & & \\
\hline Ajuda na alimentação &, $560 * *$ &, $488 * *$ &, $580 * *$ &, $564 * *$ & 1,000 & \\
\hline Escore da escala de Barthel &,$- 835 * *$ &,$- 753 * *$ &,$- 842 * *$ &,$- 739 * *$ &,$- 704 * *$ & 1,000 \\
\hline
\end{tabular}


como um moderador da tensão oriunda da situação de cuidado(8).

Além disso, verificou-se Que tanto a Qualidade da interação prévia, Quanto a da interação atual entre idoso/cuidadora geraram tensão em algumas das cuidadoras. Considerando dificuldades no relacionamento prévio com o idoso, sete $(23,3 \%)$ cuidadoras afirmaram vivenciá-las de modo freqüente e seis (20\%) ocasionalmente. A relação atual das cuidadoras com o idoso foi avaliada por Quatro $(13,3 \%)$ como freeüentemente problemática e por $10(33,3 \%)$ como casualmente difícil.

O idoso de hoje pode ser aquela pessoa jovem Que não conseguiu compreender ou se aproximar dos filhos de maneira afetuosa no passado; como tal, o fato de estar dependente, acamado ou em cadeira de rodas, não é suficiente para eliminar os traços negativos residuais Que entrelaçaram sua relação com esses filhos, ou para reconstruir laços familiares, Que nunca tiveram alicerce, à custa de piedade, doença e sofrimento ${ }^{(16)}$.

Quando cuidadores avaliam sua relação com o receptor de cuidados como caracterizada por forte vínculo de afeição, eles toleram melhor o ônus do cuidado, evidenciando, portanto, menos tensão. Além disso, esse tipo de relacionamento desperta no cuidador o desejo de prestar assistência ao idoso, não apenas devido seu compromisso como parente mas, por vontade.

\section{Determinantes Relacionados ao Ambiente}

No Que se refere ao ambiente familiar, 13 (43,3\%) cuidadoras afirmaram a vivência de problemas neste contexto antes de assumirem a atividade de cuidado, sendo cinco (16,7\%) com maior freqüência e oito $(26,7 \%)$ às vezes. Considerando a importância de relações familiares saudáveis para o alívio das pressões cotidianas e para a avaliação do ônus relacionado à provisão de cuidados, diversos autores ${ }^{(16,17)}$ apontam problemas familiares como preditores de tensão no cuidador, o que se verificou, também, nesta pesquisa.

$\mathrm{O}$ suporte social das cuidadoras era de natureza restrita. $\mathrm{O}$ suporte formal era recebido por Quatro $(13,3 \%)$ das cuidadoras. Quanto ao suporte informal, duas $(6,7 \%)$ recebiam ajuda de amigos de forma freeüente e duas $(6,7 \%)$ às vezes. 12 (40\%) não recebiam nenhuma ajuda de familiares; nove (30\%) tinham tal auxílio eventualmente e nove (30\%), eram auxiliadas freqüentemente pelos familiares. Com relação ao suporte emocional, 17 (56,7\%) cuidadoras mencionaram possuir alguém com Quem compartilhava seus sentimentos de maneira freqüente e Quatro $(13,3 \%)$ apenas ocasionalmente.

A família constitui o principal núcleo de proteção e ajuda dos idosos dependentes. Nas circunstâncias em Que este sistema, por Questões diversas, não assumia em conjunto o compromisso de prover a assistência requerida pelo idoso, acabava sobrecarregando um de seus elementos Que, por escolha ou por imposição, vivenciava solitariamente a atividade contínua de cuidar e, por sua vez, conflitos e tensão, conforme retrata este depoimento:

... Minha irmã não vem, nem liga de ver mãe... Passa ano sem vir aqui. Tudo sou eu, e é porque ela (a irmã) tem saúde. Eu disse a ela: "Você podia levar mãe, pelo menos prá fazer um exame de sangue, levar ela prá algum lugar..." Mas, não!(E9).

Na família, a pessoa, ao se engajar no papel de cuidador, o faz por um movimento de "slipping into it" (escorregar para dentro), paralelamente à ocorrência de um outro movimento desencadeado pelos demais membros do sistema Que é o "slipping out of" (escorregar para fora). Isto é, Quanto mais o cuidador se envolve no cuidado, mais os não cuidadores se desvencilham do papel ${ }^{(17)}$. No contexto desta pesquisa, observou-se que, uma vez assumido, o cuidado se tornava intransferível e, portanto, um agente prejudicial para o bem-estar daquelas Que o efetivavam.

Além do ambiente familiar e social, o ambiente físico do idoso/ cuidadora também era desfavorável. A estrutura da casa, no geral, dificultava a provisão de cuidados por apresentar as seguintes características: seis (20\%) não possuíam um Quarto exclusivo para o idoso; 16 (53,3\%) tinham piso escorregadio; 24 (80\%) não possuíam tapete antiderrapante no banheiro; 27 (90\%) não tinham barras de apoio no banheiro; e Quatro $(13,3 \%)$ casas continham degraus em sua superfície. Essas condições ambientais proporcionavam desconforto tanto para o idoso como para as cuidadoras Que, em alguns momentos, necessitavam fazer adaptações Que afetavam a privacidade de outros membros familiares para acomodar o idoso.

Os equipamentos de ajuda para o idoso ante seus problemas de locomoção eram Quantitativamente insuficientes. Nove (30\%) idosos, Que podiam ser auxiliados por andador, não possuíam tal recurso; entre os $25(83,3 \%)$ Que seriam beneficiados por cadeira para banho, apenas seis (20\%) tinham esse equipamento; dos 24 (80\%) Que apresentavam limitação física importante para locomoção, apenas cinco (16,7\%) tinham cadeira de rodas; entre os $25(83,3 \%)$ Que permaneciam maior tempo acamados, somente 12 (48\%) possuíam cama com altura ideal para implementação de cuidado no leito; finalmente com relação aos nove (30\%) idosos Que apresentavam manutenção relativa do controle de eliminação urinária, bem como da capacidade cognitiva, sete $(23,3 \%)$ possuíam urinol, equipamento mais acessível à família.

No Que tange aos recursos materiais de consumo, dos 22 $(73,7 \%)$ idosos com uso indicado de fraldas, $11(36,7 \%)$ tinham esse recurso freeüentemente e seis $(20 \%)$ às vezes. No tocante a disponibilidade de medicamentos prescritos, 15 (50\%) faziam uso sistemático e, por carência econômica, 12 (40\%) faziam interrupções na utilização da terapia e um $(3,3 \%)$ nunca podia comprar tais substâncias, apesar de necessitar. A escassez de materiais ora apresentada estava envolvida, tanto no agravamento progressivo da saúde e da incapacidade do idoso e, conseqüentemente, no aumento da demanda de cuidados, como na ocorrência de dificuldades adicionais para as cuidadoras implementarem suas ações.

\section{Determinantes Relacionados às Demandas de Cuidado}

Considerando as demandas de cuidado, 29 (96,7\%) cuidadoras tinham demanda acentuada, en $u a n t o$ uma $(3,3 \%)$ leve/moderada. Quanto às demandas objetivas, especialmente a duração temporal em Que as cuidadoras atendiam as necessidades de cuidado do idoso, identificamos o mínimo de um e o máximo de 12 anos, com um tempo médio de 4,4 (IC 95\%= $= \pm 1,25$; DP $=3,35) \mathrm{e}$ mediana de três anos. Vinte e duas $(73,3 \%)$ proviam cuidado entre um e cinco anos; seis (20\%) cuidavam do idoso num tempo de seis a dez anos; e duas $(6,7 \%)$ eram cuidadoras há mais de dez anos. No tocante ao número de horas diárias de envolvimento na provisão de cuidados, verificamos o mínimo de nove e o máximo 
de 24 horas, com uma média de 19,9 (IC 95\% = $\pm 2,21$; DP $=$ $5,92)$ e mediana de 24 horas diárias. Dez $(33,3 \%)$ cuidadoras assistiam o idoso até doze horas diárias e 22 (73,3\%), por mais de doze horas ao dia.

Essa exposição contínua das cuidadoras aos eventos estressantes da situação de cuidado implicaram alteração gradual e generalizada dos seus recursos pessoais e do seu bem-estar. Outros estudos também identificaram a associação entre maior duração do cuidado e pior Qualidade de vida do cuidador ${ }^{(6,10)}$. A Quantidade de tempo dispensado às atividades de cuidado são mais importantes no desenvolvimento de alterações físicas e emocionais no cuidador do Que o tipo de ação realizada por ele.

Devido ao elevado nível de dependência dos idosos, as cuidadoras estavam engajadas intensamente na implementação de cuidado direto ou instrumental para o atendimento das necessidades do seu familiar. Essa intensa demanda de cuidado requerida pelo familiar dependente estava envolvida tanto na realização de maior esforço físico e desconforto associado, como na ocorrência de repulsa nas cuidadoras, especialmente nas ocasiões em Que realizavam higienização do idoso, constituindo, portanto, forte antecedente de tensão.

...Tem hora que é pesado... Quando eu dava o sabonete e ela passava, dava o caneco e ela colocava água na cabeça, era melhor... Mas, agora, nada disso ela faz... Nessa hora, eu penso Que não vou agüentar muito não!... Prá limpar as fezes, meu estômago é muito ruim (EI7).

Além disso, as demandas subjetivas do cuidado, como a sensação de sobrecarga, constituíram importante preditor de tensão entre as cuidadoras investigadas. Na medida de sensação de sobrecarga, verificamos um escore mínimo de oito e máximo de 16 pontos, com média de 12,9 (IC 95\% $= \pm 0,85$; $\mathrm{DP}=2,26$ ) e mediana de 13 pontos. Considerando a intensidade individual em Que as cuidadoras manifestavam o senso de sobrecarga, duas $(6,7 \%)$ expressavam essa sensação de forma leve; 12 (40\%) se sentiam moderadamente sobrecarregada e 16 (53,3\%) evidenciavam senso de sobrecarga de maneira elevada ou total.

...Às vezes cansa... Eu me canso! Cansa muito!... A minha vontade, assim, o meu eu, é sair correndo, andar por aí (EI I).

Conforme expresso, as cuidadoras, apesar de estarem disponíveis para servir, se encontravam cansadas por realizarem múltiplas tarefas associadas ao cuidado, pela falta de tempo para si e pela escassez de suporte familiar. Quando cuidadoras se deparam com o acúmulo das demandas de cuidado com senso de sobrecarga subjacente, onde elas tendem a achar Que aQuilo Que recebem é pouco comparado à doação, é a base de "suor e lágrimas" que elas convivem com tal realidade, o Que resulta em crescente prejuízo para seu bem-estar subjetivo ${ }^{(14)}$. A sobrecarga, em todas as suas dimensões, conduziu $28(93,3 \%)$ cuidadoras a se sentirem aprisionadas ao papel.

Eu me sinto, assim, numa prisão!... Sou presa! Não só física, de não poder sair, irritada, não é?, como também no espírito, porque a gente fica tão condicionada àQuela atividade, tão preocupada com o dia de amanhã, com a incerteza! (E7).

Quando o cuidado envolve, em maior grau, a vida do cuidador, Quando ele se vê e é visto apenas como tal, e não mais como uma pessoa com identidade, gostos e desejos, sua tentativa é dar conta de preservar seus sentimentos anteriores, o Que lhe gera muita tensão(15). Além disso, Quando cuidadores se percebem sobrecarregados, tendem a sentir maiores níveis de tensão e, conseqüentemente, a desempenharem suas funções aQuém de suas capacidades, o Que resulta numa situação de cuidado desequilibrada, normalmente acompanhada por resultados insatisfatórios.

\section{CONCLUSÃO}

A análise realizada nos permite afirmar que a tensão do cuidador familiar de idosos dependentes resulta de fatores biopsicossociais, econômicos e histórico-culturais, Que se estabelecem na situação de cuidado em sua totalidade, como também no relacionamento do cuidador consigo mesmo (inclusive com seus recursos pessoais para avaliar e enfrentar tal situação) e com outras pessoas significativas, especialmente com o receptor de cuidados e com outros membros familiares. Desequilíbrio nesses fatores, materializa o fenômeno.

Considerando o exposto, ressaltamos Que a assistência ao cuidador familiar requer um redirecionamento do olhar daqueles Que planejam e executam ações cuidadativas em seu favor, no sentido de implementar intervenções Que venham minimizar o impacto da condição de dependência do idoso sobre o cuidador. O não reconhecimento dos seus problemas no sistema formal de cuidados, escamoteia suas Questões, limitando-as ao âmbito doméstico, onde, também, podem estar/ficar igualmente obscurecidas. Isso ocorre a despeito da Política de Atenção à Saúde do Idoso determinar a efetividade de um sistema de apoio e desenvolvimento de parcerias entre os serviços de saúde, os profissionais e o cuidador familiar para o enfrentamento do envelhecimento com dependência.

\section{REFERÊNCIAS}

I. Sànchez CS. La experiencia de ser cuidadora de uma persona en situción de enfermedad crônica. Invest Educación Enfermería 2001; 19(2): 36-50.

2. Karsch UMS, Leal MGS. Pesquisando cuidadores: visita a uma prática metodológica. In: Karsch UMS, organizadora. Envelhecimento com dependência: revelando cuidadores. São Paulo: Educ; 1998. p. 2 I-46.
3. Ministério da Saúde (BR). Conselho Nacional de Saúde. Resolução 196 de 10 de outubro de 1996. Diretrizes e normas regulamentadoras da pesquisa envolvendo seres humanos. Brasília: Ministério da Saúde; 1996.

4. Mahoney FI, Barthel DW. Functional evaluation: the barthel index. Rehab 1965; 1: 61-5.

5. Pearlin LI, Mullan IT, Semple SI, Skaff MM. Caregiving and the 
stress process: an overview of concepts and their measures. Gerontol 1990; 30(5): 583-94.

6. Meyers JL, Gray LN. The relationships between family primary caregiver characteristics and satisfaction with hospice care, Quality of life and burden. Oncol Nurs Forum 200 I; 28(1): 73-82.

7. Yeh S, Johnson MN, Wang S. The changes in caregiver burden following nursing home placement. Int I Nurs Studies 2002; 39: 59I-600.

8. Sànchez CS. El circulo de malestar de las cuidadoras. Cuad Mujer Salud 200 I; 6 (1): 74-7.

9. Sisk RJ. Caregiver burden and health promotion. Int I Nurs Studies 2000; 37: 37-43.

10. Chou KR. Caregiver burden: a concept analysis. J Pediatric Nurs 2000; 15(6): 398-407.

11. Schultz R, Scoott RB. Caregiving as a risk factor for mortality: the caregiver health effects study. IAMA 1999; 282(23): 22 15-9.

12. Camarano AA. Envelhecimento da população brasileira: uma contribuição demográfica. In: Freitas EV, Py L, Cançado FAX,
Doll J, Gorzoni ML. Tratado de Geriatria e Gerontologia. $2^{\mathrm{a}}$ ed. Rio de laneiro: Guanabara; 2006. p. 88-104.

13. Livingston G, Manuela M, Katona C. Depression and other psychiatric morbidity in carers of elderly people living at home. BMI 1996; 312: 153-6.

14. Neri AL, Sommerhalder C. As várias faces do cuidado e do bem-estar do cuidador. In: Neri AL, organizador. Cuidar de idosos no contexto da família: Questões psicológicas e sociais. Campinas: Alínea 2002. p. 9-64.

15. Braithwaite V. Contetual or general stress outcomes: making choices through caregiving appraisals. Gerontol 2000; 40(6): 706- 17.

16. Luders SLA, Storani MSB. Demência: impacto para a família e a sociedade. In: Papaléo Netto M. Gerontologia. Rio de Janeiro: Atheneu; 1999. p. 146-59.

17. Velasquez MD, Dalrio MC, Marques DD, Medeiros SARM. As trajetórias de vida dos cuidadores principais. In: Karsch UMS, organizadora. Envelhecimento com dependência: revelando cuidadores. São Paulo: Educ; 1998. p. 87-145. 